\title{
Türkiye İçin Endemik Calligonum polygonoides L. ssp. comosum (L'Hér.) Çalısının Otlanmada Tercih Durumları ile Bazı Bitkisel ve Verim Özelliklerinin Belirlenmesi
}

\author{
Süleyman TEMEL \\ Işıl TEMEL \\ ${ }^{1}$ Iğdır Üniversitesi Ziraat Fakültesi Tarla Bitkileri Bölümü, 76000, Iğdır \\ (*Sorumlu yazar e-mail: stemel33@hotmail.com)
}

Geliş Tarihi :24.10.2017

Kabul Tarihi :20.11.2017

\begin{abstract}
ÖZET: Bu çalışma ile Iğdır-Aralık rüzgâr erozyon sahasında doğal olarak yetişen Ebu Cehil (Calligonum polygonoides L. ssp. comosum (L'Hér.)) çalısının bazı verim ve bitkisel özellikleri ile hayvanlar tarafından otlanmada tercih durumları belirlenmiștir. $\mathrm{Bu}$ amaçla 2014 yılında Ebu Cehil çalısının yoğun olarak yetiştiği otlanan ve otlanmayan kesimler deneme alanı olarak seçilmiştir. Otlanmayan 5 dekarlı alanda parselsiz örnekleme yöntemine göre seçilen 25 çalı öbeğinde; bitki boyu (cm), sürgün uzunluğu $(\mathrm{cm})$, öbek başına dal sayısı, öbek başına yaş sürgün ve kuru sürgün verimleri $(\mathrm{kg})$ belirlenmiștir. Otlanmada tercih durumları otlanan mera kesimleri $(5 \mathrm{da})$ üzerinde yürütülmüştür. Bitkisel ve verim özelliklerinin ölçülmesinde deskriptif istatistik yöntemi, otlanmada tercih durumlarının belirlenmesinde ise gözlem yolu kullanılmıștır. Calıșma sonunda bitki boyunun $120.0 \mathrm{~cm}$ ile $225.0 \mathrm{~cm}$, sürgün uzunluğunun $45.10 \mathrm{~cm}$ ile $68.25 \mathrm{~cm}$, öbek başına dal sayısının 12.00 adet ile 19.00 adet, öbek başına yaş sürgün veriminin $19.17 \mathrm{~kg}$ ile $67.13 \mathrm{~kg}$ ve öbek başına kuru sürgün veriminin ise $5.49 \mathrm{~kg}$ ile $16.20 \mathrm{~kg}$ arasında değiştiği ortaya konulmuştur. Otlanmada tercih durumlarına bakıldığında ise bitkilerin gelişme süresi boyunca hayvanlar tarafindan yoğun bir şekilde tercih edildikleri görülmüştür. Sonuç olarak Ebu Cehil çalısının vejetasyon süresi boyunca yüksek bir büyüme gücüne, önemsenmeyecek miktarda yem materyali üretimine ve kök boğazı bölgesinde yoğun bir dallanmaya sahip olduğu belirlenmiștir. Ayrıca hayvanlar (özellikle de küęükbaş) tarafından istekle otlandıkları ortaya konulmuştur.
\end{abstract}

Anahtar kelimler: Ebu Cehil çalısı, otlanma tercihi, sürgün uzunluğu, verim

\section{Determination of Some Plant and Yield Characteristics with Preference Conditions in Grazing of Endemic Calligonum polygonoides L. ssp. comosum (L'Hér.) Shrub for Turkey}

\begin{abstract}
This study was conducted to determine the preference conditions in grazing by animals with some yield and vegetable characteristics of Ebu Cehil shrub growing naturally in Iğdır-Aralık wind erosion region. For this purpose, grazing and non-grazing areas where Ebu Cehil intensively grew were chosen as research area in 2014 . At 25 shrub groups selected according to sampling method without plot on an area of 5 decares which were not grazed by animals; plant height $(\mathrm{cm})$, twing length $(\mathrm{cm})$, number of branches per group, fresh twing and dry twing yield $(\mathrm{kg})$ were determined. The preferences of animals to grazing was carried out on grazing pastures ( $5 \mathrm{da}$ ). Descriptive statistical method was used to determine the plant and yield characteristics. At the end of the study, it ranged from 120.0 to $225.0 \mathrm{~cm}$ for plant height, from 45.10 to $68.25 \mathrm{~cm}$ for twing lenght, from 12.0 to 19.0 number for number of branches per group, from 19.17 to $67.13 \mathrm{~kg}$ for fresh twing yield per group and from 5.49 to $16.20 \mathrm{~kg}$ for dry twing yield per group. Regarding their preference by animals, it was seen that plants were intensively prefered during the development period. As a result, it was determined that Ebu Cehil shrub had a dense branching through the root zone, a high growth power and the feed material producing in amount that was negligible during the vegetation period. Also, it was revealed that Ebu Cehil was ambitiously grazed by animal (especially small ruminants).
\end{abstract}

Keywords: Ebu Cehil shrub, grazing preference, twing lenght, yield

\section{GİRIŞ}

Son y1llarda bilim insanları ve hayvancılıkla uğraşan işletmeler hayvan beslenmesinde gereksinim duyulan eksik kaba yem ihtiyacını karşılamak için alternatif ucuz ve kaliteli kaba yem arayışı içerisine girmişlerdir. $\mathrm{Bu}$ amaçla özellikle de doğada kendiliğinden yetişen kserofit ve halofit türler büyük bir avantaj olarak görülmüştür. Çünkü bu türler ekstrem iklim ve toprak koşullarında dahi büyüme ve gelişmelerini devam ettirebilmekte, otlayan hayvanlara yeter miktar ve kalitede yem materyali üretebilmektedirler (Temel, 2015; Temel vd., 2015). Ancak doğada yetişen bu türler yabanilik özelliklerini büyük oranda koruduklarından ve bu türlerle ilgili yeterli islah çalışmaları yapılmadığından hayvanlarda bazı beslenme bozukluklarına neden olabileceği de unutulmamalıdır (Tan ve Temel, 2012). Bu amaçla gerek bu türlerin ekstrem koşullarda üstün yetişebilme özelliklerinden istifade edebilmek ve gerekse hayvanlarda oluşabilecek beslenme problemlerini minimize etmek için pek çok kserofit ve halofit tür farklı 1slah çalışmalarına konu olmuş ve pek çok bilim adamı tarafından kültüre alınabilme olanakları araştırılmaya başlanmıştır. Ayrıca farklı coğrafi bölgelerde marjinal alanlarda yetişebilen türlerin verim, kalite ve bitkisel özelliklerinin belirlenmesine yönelik çalışmalara hız verilmiş, otlanma idaresi ve ıslah çalışmalarına odaklanılmıştır (Temel, 2015; Temel vd., 2015; Oktay ve Temel, 2015a).

Bilindiği üzere doğada yetişen pek çok otsu tür ve tarla ziraatında kültürü yapılan yem bitkileri ekstrem koşulların yaşandığ dönemlerde dormant döneme girmekte, yeter miktar ve kalitede yem materyali üretememektedir. Oysa doğada 
kendiliğinden yetişebilen pek çok çalı ve odunsu tür; gelişmiş kök sistemleri sayesinde kuraklığa toleransları yüksek olup, pek çok kültür bitkisinin gelişemediği alanlarda rahatça yetişebilmektedirler (Temel ve Tan, 2009; Temel, 2015). Ve bu türler sahip oldukları özellikleri sayesinde çok fazla verim ve kalite kaybına maruz kalmadan yeşilliklerini devam ettirmekte ve ruminantların beslenmesinde önemli bir alternatif yem kaynağı sağlamaktadırlar (Aganga ve Tshwenyane, 2003; Temel ve Tan, 2011a; Temel ve Tan, 2011b; Temel, 2015: Temel vd., 2015; Oktay ve Temel, 2015a; Oktay ve Temel, 2015b; Dökülgen ve Temel, 2015).

Polygonaceae familyasının bir üyesi olan Calligonum cinsi, daha çok Dünyanın kurak ve yarı kurak iklim bölgelerinde yer alan çöllerde (Kuzey Afrika'da, Batı ve Orta Asya'da, Güney Avrupa'da) yayılış göstermekte ve 80 'den fazla türü bulunmaktadır (Brandbyge, 1993; Kerven vd., 2004; Abdurahman vd., 2012; Govind vd., 2012). Bu türlerden bir tanesi de Calligonum polygonoides $\mathrm{L}$. ssp. comosum (L'Hér.) türüdür. Dünyada yayllış gösterdiği ülkelerde "Phog" olarak anılan tür, Ülkemizde Ebu Cehil çalısı olarak bilinmektedir. Türkiye için endemik olan bu çalı türü, sadece Iğdır ili Aralık ilçe sınırları içerisinde yer alan rüzgâr erozyon sahasında doğal olarak yetişmektedir. Bu tür, sahip olduğu kuvvetli ve geniş bir alana yayılım gösteren kökleriyle, kumulların tutulmasında ve erozyon kontrolünde önemli bir rol oynamaktadır (Khan, 1997; Tao, 2000; Gyssels vd., 2005; De Baets vd., 2006; Oktay, 2014). Genellikle 1-2 m ve bazen de 3 m'ye kadar ulaşabilen boya sahiptir (Jussieu, 2001; Oktay, 2014). Yine farklı araştırmacılar tarafından yapılan çalışmada Calligonum cinsine ait türlerin 1-2 $\mathrm{m}$ derine nüfuz edebilen köklere ve toprak yüzeyindeki 10 m'lik bir alana yayılıș gösteren taç çapına sahip olduğu rapor edilmiştir (Burdak, 1982; Pullaiah, 2006). Bu kurakçıl çalı türü ayrıca yüksek besin içeriğinden dolayı hayvan beslenmesinde yem kaynağı olarak kullanılmaktadır (Abdurahman vd., 2012; Abdullah vd., 2013; Oktay ve Temel, 2015a).

Mera statüsünde bulunan çalılık alanlarda en yüksek üretim potansiyelini elde etmek ve otlayan hayvanlara optimum yarar sağlayabilmek için çalılık ekosistemlerde bulunan türlerin bazı bitkisel özelliklerinin ve ürettikleri yem miktarlarının bilinmesi önemlilik arz etmektedir. Dolayısıyla bu gibi formasyonlarda öncellikle temel çalışmaların yapılması ve yem kaynaklarınının geliştirilmesi için gerekli tedbirlerin alınması gerekmektedir. $\mathrm{Bu}$ amaçla, Iğdır-Aralık rüzgar erozyon sahasından yaygın olarak yetişen Ebu Cehil çalısının otlanmada tercih durumları, bazı verim ve bitkisel özelliklerinin belirlenmesi hedeflenmiştir.

\section{MATERYAL VE METOT}

Bu çalışma, 2014 yilında Ebu Cehil çalısının yoğun olarak yetiştiği Iğdır-Aralık rüzgâr erozyon sahasında kurulmuştur. Çalışma alanı Türkiye'nin ikinci en büyük rüzgâr erozyon sahası olup (Özdoğan, 1976), 825 m rakıma sahiptir. Korunan deneme sahasından $(0-60 \mathrm{~cm})$ alınan toprak analiz sonuçlarına göre; topraklar tuzsuz (EC $0.32 \mathrm{dS} \mathrm{m}^{-1}$ ) ve hafif alkali ( $\mathrm{pH} 8.16)$ yapıda olup, kireç $(\% 0.41)$, organik madde (\%0.45) ve elverişli fosfor (1.52 ppm) içeriği düşük bulunmuştur. Ana materyal volkanik bir yapı olan rusubat karakterdedir. $\mathrm{Bu}$ özelliğinden dolayı toprak bünyesi tınlı yapıda ve verimliliği de çok düşüktür (Oktay, 2014).

Çizelge 1. Araştırma süresince denemenin yürütüldüğü alanın bazı iklim özellikleri*

\begin{tabular}{lcccccc}
\hline Aylar & \multicolumn{2}{c}{ Ortalama sıcaklık ( $\left.{ }^{\mathbf{0}} \mathbf{C}\right)$} & \multicolumn{2}{c}{ Yağıs miktarı } & mm) & \multicolumn{2}{c}{ Ortalam nispi nem (\%) } \\
\hline Mart & UYO** $^{*}$ & $\mathbf{2 0 1 4}$ & UYO & $\mathbf{2 0 1 4}$ & UYO & $\mathbf{2 0 1 4}$ \\
Nisan & 7.2 & 10.1 & 20.6 & 17.2 & 46.1 & 46.8 \\
Mayıs & 13.5 & 15.7 & 44.8 & 30.5 & 47.1 & 46.6 \\
Haziran & 17.9 & 19.6 & 50.7 & 49.9 & 48.4 & 52.3 \\
Temmuz & 22.9 & 23.5 & 31.7 & 34.6 & 42.3 & 42.3 \\
Ağustos & 26.4 & 27.7 & 15.4 & 7.7 & 40.0 & 38.2 \\
Eylül & 26.4 & 28.1 & 9.6 & 5.0 & 40.7 & 36.0 \\
Ekim & 20.6 & 22.4 & 12.7 & 15.2 & 46.7 & 42.6 \\
Top./Ort. & 13.7 & 13.6 & 21.8 & 27.1 & 58.9 & 66.1 \\
\hline
\end{tabular}

*MGM, 2015, **UYO: Uzun Yillar Ortalaması

Uzun yıllar ortalamasına göre bölgenin yıllık yağış miktarı $207.3 \mathrm{~mm}$, nispi nem miktarı \%46.3 ve sicaklık ise ortalama $18.6{ }^{\circ} \mathrm{C}$ 'dir (MGM, 2015). Bu veriler dikkate alındığında De Martone Kuraklık indisine göre bölge çok kurak bir iklim özelliğine sahiptir (Gençtan, 2012). Araştırmanın yürütüldüğü dönemde ise bölgenin toplam yıllık yağış miktarı, oralama sicaklık ve nispi nem değerleri sirasıyla 
$187.2 \mathrm{~mm}, 20.1{ }^{\circ} \mathrm{C}$ ve \%46.4 olarak ölçülmüştür (Çizelge 1). $\mathrm{Bu}$ sonuçlara göre denemenin yürütüldüğü dönemler, uzun yıllar ortalamasına göre daha kurak geçtiği görülmüştür. Araştırma hayvanlar tarafından otlanmayan 5 dekarlık bir alan üzerinde parselsiz örnekleme yöntemine göre seçilen 25 çalı öbeğinde yürütülmüştür. Çalı öbekleri mevcut alanda yer alan çalı topluluklarını temsil edecek şekilde seçilmiştir. Çalı öbekleri üzerinde bitki boyu $(\mathrm{cm})$, öbek başına yaş sürgün verimi (kg), öbek başına kuru sürgün verimi $(\mathrm{kg})$, öbek başına dal sayısı (adet) ve sürgün uzunlukları (cm) belirlenmiştir. Ölçümler vejetasyon dönemi sonu olan ekim ayında yapılmıştır.

Ebu Cehil çalısında yaprak oluşumu bulunmamakta ve yıl içerisinde oluşturulan toprak üstü biomasın hepsi sürgün yapısındadır. Ayrıca Ebu Cehil çalısının hayvanlar tarafından otlanan ve hayvanlara yem kaynağı sağlayan kısımları sürgünleridir. Dolayısıyla bu çalışma kapsamında incelenen Ebu Cehil çalısında ot verimi terimi yerine sürgün verimi ifadesi kullanılmıştır. Doğal vejetasyonlarda yetişen çalı ve ağaç türlerinde toprak üstü biomas üretimini tahmin etmek hem zaman almakta hem de fazla iş gücü gerektirmektedir. Bundan dolayı bu formasyon tiplerinde kolay bir şekilde ölçülebilen özellikler kullanarak, allometrik eşitlikler yardımıyla kütle tahmin etme yöntemi kullanılmıştır (Sah vd., 2004; Temel ve Tan, 2011b). $\mathrm{Bu}$ amaçla sürgün gelişiminin sonlandığı yaz döneminde deneme kapsamında belirlenen her çalı öbeğinden mevcut çalı öbeğini temsil edecek şekilde bir adet dal belirlenmiştir. Sonra bu dal üzerindeki sürgünler (mevcut yetişme süresi içerisinde gelişme gösteren) elle toplanmış ve bez torbalara konulmuştur. Daha sonra arazi tipi hassas terazide tartılarak, yaş sürgün verimleri $\mathrm{kg}$ cinsinden belirlenmiştir. En son aşamada ise mevcut sürgün verimi öbekte yer alan toplam dal sayısı ile çarpılıp, öbek başına toplam yaş sürgün verimi hesaplanmıştır. Öbek başına kuru sürgün verimini belirlemek için; yaş sürgün verimi belirlenen örnekler önce açık havada ve sonra $65{ }^{\circ} \mathrm{C}$ 'ye ayarlı kurutma firınında ağırlıkları sabit oluncaya kadar kurutulmuş ve daha sonra kuruyan örnekler laboratuvar tipi hassas terazide tartılarak kuru sürgün verimleri kg cinsinden belirlenmiştir. Öbek başına toplam kuru sürgün veriminin belirlenmesinde de yaş sürgün verimi için belirlenen yol takip edilmiştir. Ebu Cehil bitkisi kök boğazından bol miktarda dal meydana getiren ve vejetasyonda contagius dağılışı göstererek, öbekler halinde gelişme gösteren bir çalı türüdür. Dolayısıyla öbek başına dal sayısı belirlenirken, araştırma sahasından belirlenen her bir öbekte kök boğazından çıkan dal sayılarının sayılması şeklinde bir yol izlenmiştir. Vejetasyon dönemi sonunda bitkinin ana sap üzerinde o yıl oluşturduğu sürgün uzunluklarının ölçülmesiyle de sürgün uzunlukları ölçülmüştür. Bu amaçla her bir çalı öbeğinde yaş sürgün verimi için temsili olarak seçilen ana dal üzerindeki her bir sürgünün uzunluğu $\mathrm{cm}$ cinsinden ölçülmüş ve daha sonra bu sürgün uzunluklarının toplamı ana dal üzerindeki sürgün sayısına oranlanarak ortalama sürgün uzunlukları belirlenmiştir.

Ebu Cehil çalısının otlanmada tercih durumlarının belirlenmesi ise yine 5 dekarlık bir alan üzerinde hayvanlar tarafindan sürekli otlanan kesimler üzerinde yürütülmüştür. Hayvanlar tarafindan tercih edilme durumları bitkilerin vejetasyon süresi boyunca aktif olarak geliştikleri 2014 yılı Nisan ayı ile 2014 yılı Ekim ayı arasında 15 günlük arazi turları ile belirlenmiştir. Araştırma sahasında Ebu Cehil çalısının otlanmada tercih durumları gözlem yolu ile belirlenmiş ve bu amaçla Güven (2004) tarafindan geliştirlen sıkala kullanılmıştır.

Çizelge 2. Ebu Cehil çalısının otlanma durumunun belirlenmesinde kullanılan sıkala

\begin{tabular}{|c|l|}
\hline Puan & Otlanma durumu \\
\hline 0 & Tercih edilmeyen (hiç otlanmamış) \\
\hline 1 & Çok az tercih edilen (sürgünlerin \%0-25'inde otlanma belirtisi) \\
\hline 2 & Az tercih edilen (sürgünlerin \%26-50'sinde otlanma belirtisi) \\
\hline 3 & Orta derecede tercih edilen (sürgünlerin \%51-75'inde otlanma belirtisi) \\
\hline 4 & S1k tercih edilen (sürgünlerin \%76-100'ünde otlanma beliritisi) \\
\hline
\end{tabular}

Ebu Cehil çalısına ait bitki boyu, öbek başına yaş sürgün verimi, kuru sürgün verimi, kök boğazında çıkan öbek başına dal sayısı ve mevcut vejetasyon süresi içerisinde büyüyen sürgün uzunluklarını belirlemek için deskriptif (tanımlayıcı) istatistik yöntemi kullanılmıştır (Yıldız ve Bircan, 1994).

\section{BULGULAR VE TARTIŞMA}

Rüzgâr erozyon sahasında 25 çalı öbeği üzerinden elde edilen veriler istatistiki analize tabii tutulmuş ve analiz sonucu incelemeye alınan bitkisel parametrelere ait değerler minimum, maksimum, ortalama ve standart sapma şeklinde verilmiştir (Çizelge 3). 
Türkiye İçin Endemik Calligonum polygonoides L. ssp. comosum (L’Hér.) Çalısının Otlanmada Tercih Durumları ile Bazı Bitkisel ve Verim Özelliklerinin Belirlenmesi

Çizelge 3. Ebu Cehil çalısının bitkisel özelliklerine ait istatistik analiz sonuçları

\begin{tabular}{lcccc}
\hline Özellikler & Minimum & Maksimum & Ortalama & Std. Sapma \\
\hline Bitki Boyu (cm) & 120.00 & 225.00 & 158.75 & 30.25 \\
Öbek Başına Yaş Sürgün Verimi (kg) & 19.17 & 67.13 & 38.73 & 14.37 \\
Öbek Başına Kuru Sürgün Verimi (kg) & 5.49 & 16.20 & 10.23 & 3.29 \\
Öbek Başına Dal sayısı (adet) & 12.00 & 19.00 & 15.65 & 1.69 \\
Sürgün Uzunluğu (cm) & 45.10 & 68.25 & 58.65 & 5.69 \\
\hline
\end{tabular}

Bitki boyu (cm): Yapılan analiz sonucu Ebu Cehil çalısının minimum, maksimum ve ortalama bitki boyları sirasıyla $120.00 \mathrm{~cm}, 225.00 \mathrm{~cm}$ ve $158.75 \mathrm{~cm}$ olarak belirlenmiştir (Çizelge 3). Oktay (2014) benzer ekolojide yürüttüğü bir çalışmada Ebu Cehil çalısının ortalama taç içi bitki boyunun $85.0 \mathrm{~cm}$ ile $145 \mathrm{~cm}$ arasında, taç dışı bitki boyunun ise 85.0 $\mathrm{cm}$ ile $230 \mathrm{~cm}$ arasında değiştiğini ortaya koymuştur. Yine Jussieu (2001), Calligonum polygonoides bitkisinin ortalama bitki boyunun 1-2 m olduğunu, bazen de 3 m'ye kadar ulaşabildiğini rapor etmiştir. $\mathrm{Bu}$ sonuçlar bizim çalışmamızda elde ettiğimiz sonuçlarla benzerlik göstermektedir. Ancak ekolojik koşullarda kendiliğinden yetişen, özellikle çalı ve ağaç formundaki bitkiler, gerek toprak (tekstürstrüktür yapısı, nemlilik ve besin maddesi durumu), topoğrafik yapı (rakım, bakı) ve iklim (sıcaklık, yağış ve 1şık) gibi çevre şartlarından gerekse canlı faktörlerin baskısından (insanlar tarafindan yakacak amacıyla kesilmesi ve sökülmesi, hayvanlar tarafından erken ve aşırı otlama gibi) kaynaklanan sebeplerden dolayı, kültürü yapılan türlerde olduğu gibi standart bir bitki boyundan bahsetmek mümkün değildir.

Öbek başına dal sayısı (adet): Ebu Cehil çalısının kök boğazı bölgesinde toprak yüzeyine çıkış yapan minimum, maksimum ve ortalama öbek baş1 dal say1s1 $12.00,19.00$ ve 15.65 adet olarak tespit edilmiştir (Çizelge 3). Bitkilerin kök boğazı bölgesinde yüksek bir dallanmanın oluşması genetik yapıya bağlı olabileceği gibi yetişmiş oldukları ortamdaki iklim ve toprak özelliklerinin yapısından da kaynaklandığı söylenebilir. Çünkü bu gibi ekstrem koşulların yaşandığı bölgelerde yetişen bitkiler hayatta kalmak için toprak altı organlarını kuvvetlendirmekte ve daha geniş bir alana köklerini yaymaktadırlar (Govind vd., 2012). Örneğin kserofit türler, oluşan kuraklıklarda topraktaki nemin düşük olmasından dolayı daha kuvvetli ve daha geniş bir alanda kök uzaması ve yayılımı göstermektedirler (Reader vd., 1993; Padilla vd., 2007). Konu ile ilgili olarak Jussieu (2001) Calligonum polygonoides bitkisinin ortalama 30-60 cm, Burdak (1982) ise 10 m genişliğe kadar bir alanda yayılış gösterdiğini belirtmişlerdir. Benzer sonuçlar Oktay (2014) tarafindan da ortaya konulmuş ve Ebu Cehil bitkisinin 3.31 m'lik bir alanda öbek olarak yayılış gösterdiğini ifade etmiştir.

Sürgün uzunluğu (cm): Ebu Cehil çalısının bir vejetasyon süresi içerisinde geliştirdiği sürgün uzunluğu minimum $45.10 \mathrm{~cm}$, maksimum $68.25 \mathrm{~cm}$ ve ortalama $58.65 \mathrm{~cm}$ olarak ölçülmüştür (Çizelge 3). Ebu Cehil çalısında yaprak oluşumu bulunmamakta ve yıl içerisinde oluşturdukları toprak üstü biomasın hepsi sürgün yapısındadır. Oluşan sürgünler büyüme dönemi başlangıcı olan ilkbahar ve sonrasına tekabül eden yaz aylarında genellikle sukkulent yapıda, sonbahar aylarında ise olgunlaşmayla birlikte lif ve lignin birikiminin artmasından dolayı daha sert bir yap1 kazanmaktadır (Dökülgen ve Temel, 2015). Dolayisıyla ilkbahar ve yaz aylarında oluşan bu sukkulent sürgünler bölgede otlayan hayvanlar için önemli bir yem kaynağı durumundadırlar. Ayrıca Ebu Cehil çalısının meydana getirdiği bu sürgünler, toprak yüzeyinde malç etkisi yaparak hem toprağın yerinde tutulmasını sağlamakta hem de evaporasyon oranını düşürerek taç içi bölgesinde toprağın daha nemli kalmasını sağlamaktadır. Yine otlanan kesimlerde yapılan gözlemler sonucu otlanan sürgünlerin yeniden büyüme gösterdikleri görülmüştür. $\mathrm{Bu}$ da iyi bir otlatma idaresi ile Ebu Cehil çalısının yıl içerisinde uzun bir süre hayvanlara otlayabilecekleri bir yeşil yem materyali sağlayabileceği düşünülmektedir.

Öbek başına yaş sürgün verimi (kg): Ebu Cehil çalısının yetiştiği bölge Türkiye'nin ikinci en büyük rüzgâr erozyon sahası olup, düşük yağışa, yüksek sıcaklık ve buharlaşma oranına sahiptir. Ayrıca ana materyalin volkanik bir yapı olan rusubat karakterde olmasından dolayı toprak bünyesi tınlı yapıda ve verimliliği de çok düşüktür. Böyle bir habitat da özellikle otsu türler kısa bir süre zarfında yeşilliklerini ve dolayısyla verim ve kalitelerini hızla kaybetmektedirler. Ancak bu gibi ekolojik koşullara uyum sağlamış pek çok çalı türleri sahip oldukları özellikle kuvetli kök sistemleri sayesinde büyüme ve 
gelişmelerine devam ettirmekte ve verimlerinde de çok fazla bir düşüş yaşanmamaktadır (Temel ve Tan, 2011b; Tan ve Temel, 2012; Dökülgen ve Temel, 2015). Mevcut bu araştırmamızda da Ebu Cehil çalısı öbek başına bir yetişme süresi içerisinde minimum, maksimum ve ortalama sirasiyla $19.17 \mathrm{~kg}, 67.13 \mathrm{~kg}$ ve $38.73 \mathrm{~kg}$ yaş sürgün verimi ürettikleri belirlenmiştir (Çizelge 3). Diğer taraftan kullanım şartları (yakacak olarak sökme, aşırı otlatma v.b.) ve yetiştiği ortam koşullarının farklılık göstermesine bağlı olarak bir dekarlık alanda toplam 16 ile 20 arasında Ebu Cehil çalı öbeğinin yer aldığı tespit edilmiştir. Buna göre yapılan basit bir hesaplama ile de bir dekarlık alanda ortalama $620 \mathrm{~kg}$ ile $775 \mathrm{~kg}$ arasında bir yem materyalinin üretildiği söylenebilir. Yapılan gözlemler sonucu bölge halkının Ebu Cehil çalısını vejetasyon süresi boyunca hayvanlarına yaş olarak otlattıkları, tarla ziraatı yetiştiriciliğinde ve çayır alanlarında olduğu gibi oluşan toprak üstü biomasın biçilip kurutulmadığı görülmüştür. Dolayısıyla Ebu Cehil çalısının bitki başına oluşturduğu bu yem kütlesi, bölgede otlayan hayvanlar için özellikle yeter miktar ve kalitede yem sıkıntısının yaşandığı yaz ve sonbahar dönemlerinde önemli bir yem kaynağı olarak görülebilir.

Öbek başına kuru sürgün verimi (kg): Ebu Cehil çalısının öbek başına yıl içerisinde ürettikleri kuru sürgün verimi minimum, maksimum ve ortalama sirasiyla $5.49 \mathrm{~kg}, 16.20 \mathrm{~kg}$ ve $10.23 \mathrm{~kg}$ olarak belirlenmiştir (Çizelge 3). Her ne kadar Ebu Cehil çalısından elde edilen yem materyali bölge hayvancılığ tarafindan kuru yem olarak kullanılmasa da öbek başına elde edilen kuru yem kütlesinin yüksek olması hayvanların yem temini yaşadığ 1 kış döneminde Ebu Cehil çalısının önemli bir yem kaynağ1 olabileceğini göstermiştir. Konu ile ilgili olarak Temel ve Tan (2011b) yarı kurak iklim özelliğine sahip Akdeniz bölgesi makiliklerde yetişen 10 farklı çalı ve ağaç türünün yaprak verimlerini belirlemişler ve araştırmacılar bitki başına kuru yaprak verimlerinin $0.37 \mathrm{~kg}$ ile $12.58 \mathrm{~kg}$ arasında değiştiğini ortaya koymuşlardır. $\mathrm{Bu}$ sonuçların mevcut çalışmamızda elde edilen sonuçlarla benzerlik göstermemesi incelemeye alınan türlerin genetik yapılarının ve yetiştikleri bölgelerin ekolojik koşullarının farklı olmasından kaynaklandığı düşünülmektedir. Ayrıca çalışmada incelemeye alınan yem materyallerinin farklı olması buna neden olmuş olabilir.

Otlanmada tercih durumu: Araştırmanın yürütüldüğü alan mera statüsünde olup, hayvancılıkla uğraşan bölge halkı hayvanlarını sürekli bu alanlarda otlatmaktadırlar. Bitkilerin aktif olarak geliştiği nisan ayından ekim ayına kadar olan süre zarfinda yapılan gözlemler sonucu hayvanlar, Ebu Cehil çalısı sürgünlerinin büyük bir kısmını (\%76'sından fazla) otladıkları ve sık tercih edilen grupta yer aldıkları gözlemlenmiştir. Hatta vejetasyon dönemi sonunda bitkiler üzerinde sadece önceki y1llardan kalan ligninleşmiş kısımların (dalların) kaldığı ve bitkilerin firça görüntüsü aldığı görülmüş̧tür.
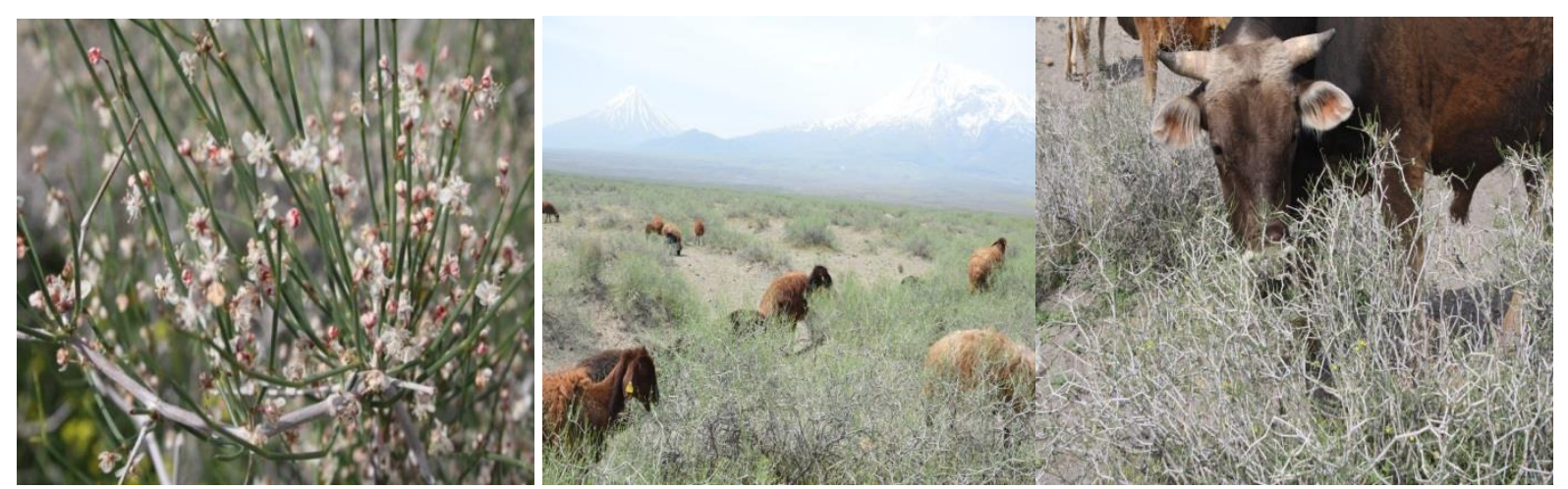

Şekil 1. Ebu Cehil çalısı ve hayvanlar tarafından otlanması

Farklı ekolojilerde çalı ve ağaç türlerinin otlanmada tercih durumlarını belirlemek üzere yürütülen çalışmalarda da hayvanların öncelikli olarak bitkilerin taze yaprak ve sürgünlerini tercih ettikleri ifade edilmiştir (Temel ve Tan, 2009; Temel ve Kir, 2015). Özellikle ilkbahar ve yaz başlangicında mevcut sürgünlerin hayvanlar tarafından daha fazla tercih edildiği ortaya konulmuştur. $\mathrm{Bu}$ da oluşan sürgünlerin bu dönemde sukkulent yapıda olmasından kaynaklandığı düşünülmektedir. Çünkü genç ve sukkulent yapıdaki materyaller olgunlaşmanın ilerlemesiyle oluşan yem materyallerine göre daha az oranda lif ve lignin içermekte ve hayvanların daha fazla tercih etmesine neden olmaktadır (Barrosa vd., 1995; Temel ve Tan, 2009; Dökülgen ve Temel, 2015). Otlanmada bölgede yaygın olarak yetiştiriciliği yapılan küçükbaş hayvanların yanında büyükbaş hayvanların da bitkinin ulaşabildikleri kısımlarını severek otladıkları gözlemlenmiştir. 


\section{SONUC}

Ebu Cehil çalısı kök boğazı bölgesinde fazla miktarda dal (sürgün) meydana getiren bir formasyon tipidir. $\mathrm{Bu}$ özelliği ile ekstrem toprak ve iklim koşullarının yaşandığı özellikle kumul hareketliliğinin yaygın olduğu alanlarda iyi bir rüzgar perdesi olarak kullanılabileceğini göstermiştir. Bitkilerin fazla bir boylanma göstermemeleri ve bitki aksamlarına rahatlıkla hayvanların ulaşabilmeleri nedeniyle iyi bir otlatma idaresi ile mevcut çalılıkların hayvanlar için iyi bir otlatma alanı olabileceği kanısı oluşmuştur. Ebu Cehil çalısının vejetasyon süresi içerisinde iyi bir sürgün gelişimi gösterdikleri ve otlanma sonrası da sürgün gelişimlerine devam ettikleri, bu özelliklerinden dolayı da otlayan hayvanlara daha uzun bir otlanma firsatı sağladıkları ortaya konulmuştur. Bölgenin toprak ve iklim özellikleri dikkate alındığında ortamda yetişen otsu türler dormant dönemde iken, Ebu Cehil çalısının rahatlıkla yetişebilmesi ve yeter miktarda yem materyali üretebilmesi, yine Ebu Cehil çalısının vejetasyon süresi boyunca hayvanlar tarafindan yoğun bir şekilde tercih edilmesi sonucu bu bitkinin bu ve benzeri bölgelerde otlayan hayvanlar için iyi bir alternatif yem kaynağ olabileceği görülmüştür.

\section{KAYNAKLAR}

Abdullah, M., Khan, R.A., Yaqoob, S., Ahmad, M., 2013. Mineral profile of browse species used as feed by grazing livestock in Cholistan Rangelands, Pakistan. Pakistan Journal of Nutrition, 12(2):135-143.

Abdurahman, M., Sabirhazi, G., Liu, B., Yin, L., Pan, B., 2012. Comparison of five Calligonum species in tarim basin based on morphological and molecular data EXCLI. Journal, 11: 776-782

Aganga, A.A., Tshwenyane, S.O., 2003. Feeding values and anti nutritive factors of forage tree legumes. Pakistan Journal of Nutrition, 2(3): 170-177.

Barroso, G.F., Alados, C.L., Boza, J., 1995. Food selection by domestic goats in Mediterranean arid shrublands. J. Arid Env., 3: 205-217.

Brandbyge, J., 1993. Polygonaceae. In K. Kubitzki, J.C. Rohwer \& V. Bittrich (eds.). The families and genera of vascular plants, Springer-Verlag, Berlin

Burdak, L.R., 1982. Recent advances in desert afforestation, Dehradun, p.56

De Baets, S., Poesen, J., Gyssels, G., Knapen, A., 2006. Effect of grass roots on the erodibility of top soils during concentrated flow. Geomorphology, 76: 54-67.

Dökülgen, H., Temel, S., 2015. Yapragını döken karaçalı (Palirus spina-christi Mill.) türünde yaprak ve yaprak+sürgünlerinin mevsimsel besin içeriği değişimi. Iğdır University Journal of the Institute of Science and Technology, 5(3): 57-65.

Gençtan, T., 2012. Tarımsal Ekoloji. Namık Kemal Üniv. Ders Kitabı. Genel Yayın: 6 Yayın No:3, Tekirdağ

Govind, V.K., Kumar, V., Sharma, R., Sharma, R.A., Sharma, S., Singh, J.P., Kumar, S., 2012. Chemical and genetic diversity among some wild stands of Calligonum polygonoides (Polygonaceae) from the Thar Desert of Rajasthan. Rev. Biol. Trop. (Int. J. Trop. Biol.), 60 (3): 1097-1108
Güven, M., 2004. Kargapazarı Dagı Florasında Bulunan Çalı Türlerinin Tespiti ve Çoğaltma Teknikleri ile Yem Değerlerinin Belirlenmesi (Doktora Tezi). Atatürk Üniv. Fen Bil. Enst. Tarla Bit. Anabilim Dalı, Erzurum.

Gyssels, G., Poesen, J., Bochet, E., Li, Y., 2005. Impact of plant roots on the resistance of soils to erosion by water: A review. Prog. Phys. Geogr, 29: 189-217.

Jussieu, A.L., 2001. Polygonaceae, No. 205. Flora of Pakistan, Karachi University, Karachi.

Kerven, C., Alimaev, I.I., Behnke, R., Davidson, G., Franchois, L., Malmakov, N., Mathijs, E., Smailov, A., Temirbekov, S., Wright, I., 2004. Retraction and expansion of flock mobility in Central Asia: Costs and Consequences. African Journal of Range \& Forage Science, 21: 159-169.

Khan, T.I., 1997. Conservation of biodiversity in western India. Environmentalist, 17: 283-287

MGM., 2015. T.C. Devlet Meteoroloji İşleri Genel Müdürlüğü Verileri, Ankara.

Oktay, G., 2014. Igdır Ekolojik Koşullarında Yetişen Ebu Cehil (Calligonum polygonoides L. ssp. comosum (L'hér.)) Çalısının Yıılık Besin İçeriği Değişiminin ve Bazı Özelliklerinin Belirlenmesi (Yüksek Lisans Tezi). Iğdır Üniv. Fen Bil. Enst. Tarla Bit. Anabilim Dalı, Iğdır.

Oktay, G., Temel, S., 2015a. Ebu Cehil (Calligonum polygonoides L. ssp. comosum (L'Her.) çalısının yıllık yem değerinin belirlenmesi. Journal of Agricultural Faculty of Gaziosmanpaşa University, 32(1): 30-36.

Oktay, G., Temel, S., 2015b. Otlatma idaresi açısından Ebu Cehil (Calligonum polygonoides L. ssp. comosum (L'Hér.)) çalısının fenolojik seyrinin belirlenmesi. Journal of Agricultural Faculty of Gaziosmanpasa University, 32 (2): $1-6$.

Özdoğan, N., 1976. Rüzgar Erozyonu ve Rüzgar Erozyonu Sahalarında Alınacak Başlıca Tedbirler. Topraksu Genel Müdürlüğü Yayınları, 306, Ankara.

Padilla, F.M., Juan de Dios, M., Pugnaire, F.I., 2007. Early root growth plasticity in seedlings of three Mediterranean woody species. Plant Soil, 296: 103-113.

Pullaiah, T., 2006. Encyclopedia of World Medicinal Plants. Vol. I. Regency Publications, New Delhi, India.

Reader, R.J., Jalili, A., Grime, J.P., Spencer, R.E., Matthews, N.N., 1993. A comparative study of plasticity in seedling rooting depth in drying soil. J. Ecol., 81: 543-550.

Sah, J.P., Ross, M.S., Koptur, S., Snyder, J.R., 2004. Estimating aboveground biomass of broadleaved woody plants in the in the understory of Florida Keys pine forests. Forest Ecology and Management, 203: 319-329.

Tan, M., Temel, S., 2012. Alternatif Yem Bitkileri. Atatürk Üniversitesi Ziraat Fakültesi, Ders Notları, Erzurum, 238 s.

Tao, L., 2000. Genetic Diversity and Systematical Taxonomy of Genus Calligonum L. PhD Thesis, Environment and Engineering Institute of Cold and Arid Regions, The Chinese Academy of Sciences, PR China, $281 \mathrm{p}$.

Temel, S., 2015. Vejetatif ve tohum olgunlaştırma döneminde Salsola tragus L. ve Noaea mucronata (Forssk.) Asch.\& Schweinf.'nin yem kalite özelliklerinin belirlenmesi. International Journal of Agriculture and Wildlife Science, 1(1): 23-30.

Temel, S., Kır, A.E., 2015. Bazı çalı ve agaç türlerinin mevsimsel dönem ve hayvan gruplarına göre otlanmada tercih durumlarının belirlenmesi. International Journal of Agriculture and Wildlife Science, 1(1): 31-39.

Temel, S., Sürmen, M., Tan, M., 2015. Effects of growth stages on the nutritive value of specific halophyte species in saline grasslands. The Journal of Animal and Plant Sciences, 25(5): 1419-1428.

Temel, S., Tan, M., 2009. Farklı yöney ve rakımda bulunan makiliklerdeki çalı türlerinin otlanmada tercih durumları üzerine bir araştırma. 6. Ulusal Zootekni Bilim Kongresi, 474-481. 
S. Temel, I. Temel

Temel, S., Tan, M., 2011a. Fodder values of shrub species in maquis in different altitudes and slope aspects. The Journal of Animal and Plant Sciences, 21(3): 508-512.

Temel, S., Tan, M., 2011b. Determination of the leaf yields and leaf ratios per plant depending on altitude and slope aspects of shrub species in Mediterranean Region maquis. Journal of the Faculty of Veterinary Medicine, Kafkas Uni., 17(2): 257-262.
Yıldız, N., Bircan, H., 1994. Araştırma ve Deneme Metotları. II Baskı. Atatürk Üniversitesi Yayınları No: 697. Erzurum. 